\title{
Geleneksel Sürdürülebilir Yağmur Suyu Depolama Yöntemleri; Emine-Murat Cimrin Koçak Evi Sarnıcının İncelenmesi ve Yeniden Kullanımının Değerlendirilmesi
}

\author{
Elif Gizem YETKINN ${ }^{1}$, Nilgün AKMAN ${ }^{2}$
}

Öz

İnsanoğlunun varoluşundan bu yana en büyük gereksinimlerinden biri olan ve yeri hiçbir şey ile doldurulamaz olan su, yapılı çevrenin oluşumunda da büyük rol oynamıştır. Yerleşimler çoğunlukla suya yakın alanlarda kurulmuştur. Ancak her yörenin kendi gereksinimleri vardır ve yerleşimler oluşurken yaşayan toplulukların temel aldıkları noktalar değişiklik göstermiştir. Ama bu su ihtiyacının önemsenmediği anlamına gelmemektedir. Suya olan ihtiyacın bu denli önemli olmasına rağmen su kaynağının olmayışı ya da su kaynağı bölgelerinde yaşam tehlikesi oluşması nedeniyle tarih boyunca tatlı su kaynaklarına uzak yerleşimlerde gelişmiştir. Temiz ve tatlı suya uzak olarak yerleşimi inşa etmiş toplumlar bu alandaki gereksinimlerini karşılamak için çeşitli stratejiler geliştirmiştir. Bunlardan en önemlisi yağmur suyu kullanımıdır. Yüzyıllar boyunca temiz ve tatı su kaynağı olarak kullanılan yağmur suyu gerek yapıların çatılarından gerekse düz alanlardan toplanarak sarnıçlarda biriktirilerek kullanılmıştır. Bu kullanıma "su hasadı" da denmektedir. Tarihi pek çok alanda yağmursuyu toplama sarnıçlarına rastlanmaktadır. Yağmur suyu hasadı, hem geçmişte hem de günümüzde en yaygın olarak kullanılan çevre dostu su elde etme yöntemlerinden biridir. Günümüzde de artan su ihtiyacı ve su kaynaklarının azalması nedeniyle su korunumu sağlamak için yağmur suyu hasadı yapabilecek benzer sistemler sürdürülebilirlik bağlamında yeni yapılan yeşil yapılarda su korunumu kapsamında uygulanmaktadır. Bu çalışmada ülkemizin önemli tarihi alanlarından biri olan ve tarihi su sistemleri ile büyük ilgi uyandıran Alanya Kalesi'nde bulunan Emine-Murat Cimrin Koçak evi sarnıç sistemi incelenmiş ve yeniden kullanım durumu hakkında değerlendirme yapılmıştır.

Anahtar Kelime: Tarihi Yapılar, Sarnıç, Yağmursuyu Toplama Sistemleri, Alanya Kalesi.

\section{Traditional Sustainable Rainwater Storage Methods; Investigation and Reuse Evaluation of Emine-Murat Cimrin Koçak House Cistern}

\begin{abstract}
\footnotetext{
${ }_{1}^{1}$ Alanya HEP Üniversitesi, Mimarlık Fakültesi, Mimarlık Bölümü, Antalya, Türkiye

${ }^{2}$ Alanya Belediyesi, Kültür Müdürlüğü, Antalya, Türkiye

İlgili Yazar/Corresponding author: gizemtelli@gmail.com

Gönderim Tarihi / Received Date: 06.07.2021

Kabul Tarihi / Accepted Date: 21.12.2021
}

Water, which has been one of the greatest necessities of human beings since its existence and cannot be filled with anything, has also played a primary role in the formation of the built environment. Settlements are mostly established in areas close to water. However, each region has its own needs, and the bases of living communities differed as settlements were formed. But this does not mean that water needs are ignored. Although the need for water is so important, it has developed in settlements far from fresh water resources throughout history due to the lack of water resources or the danger of life in the water source regions. Societies that have built settlements far from clean and fresh water have developed various strategies to meet their needs in this area. 
The most significant of these is the use of rain water. Rainwater, which has been used as a clean and fresh water source for centuries, was collected from the roofs of buildings and flat areas, and was used in cisterns. This use is also called "water harvesting". In many historical areas, rainwater collection cisterns can be found. Rainwater harvesting is one of the most widely used environmentally friendly water harvesting methods, both in the past and today. Similar systems that can harvest rainwater in order to provide water conservation due to the increasing need for water and the decrease in water resources are applied within the scope of water conservation in newly built green buildings in the context of sustainability. In this study, Emine-Murat Cimrin Koçak House cistern system in Alanya Castle, which is one of the most important historical areas of our country and attracts great attention with its historical water systems, was examined and an evaluation was made about the re-use situation.

Keywords: Historical Buildings, Cistern, Stormwater Collection Systems, Alanya Castle.

\section{Giriş}

Su insanlığın hayat kaynağı olarak tanımlanır ve tüm toplumlar suya olan bu ihtiyaca cevap olması için çeşitli su stratejileri geliştirmişlerdir. Bunlardan en etkin çözümlerinden biri sağlıklı bir su kaynağının yakınlarına yerleşmek ve yaşamı burada idame ettirmektir. Bir diğeri ise su kaynağının olmadığı ya da çok uzak olduğu bölgelerde yağmur suyunun toplanmasıdır. Yağmur suyu toplamada en kolay yöntem sarnıç sistemleri olmuştur. Sarnıç sistemlerinin neolitik çağ döneminden bu zamana kadar kullanıldığı bilinmektedir ve bu süreçte gelişerek günümüze kadar gelmiştir. Sarnıçların yapım şekillerinde ve kullanım biçimlerinde bulundukları coğrafya çok belirleyici bir unsur olmuştur. Ülkemizde sayısız sarnıç yapısı olduğu bilinmektedir. Basit kil alanlardan büyük yeraltı yapılarına kadar çok çeşitli yapım teknolojisi kullanarak inşa edilmiştir. Sarnıçlar su intiyacını karşılarken mevsimsel değişimlere bağlı yağmur yağışlarındaki dengesizliğin neden olduğu taşkınların engellenmesinde de büyük rol oynamıştır. Sarnıçların teknolojileri ve yönetim uygulamaları günümüz ve gelecek için su kaynaklarının sürdürülebilirliği açısından öneme sahiptir.

Neolitik Çağa kadar uzanan çok eski bir geçmişi olan sarnıçlar döneminin teknolojik gelişiminin bir göstergesi olarak kabul edilir. Bu sistemler çok kapsamlı hazırlanmış sistemlerdir. Kimi zaman bir evin özel su intiyacını karşılamak için kullanılmış, kimi zaman da bir yerleşimin tamamının su gereksinimini karşılamıştır.

Sarnıçlar yağmur suyu toplama uygulamalarının en önemlilerinden biridir. Bu sistemler yağmurun düştüğü yüzeylerdeki suyu toplar ve daha sonra bu suyu kullanılmak üzere depolanmasını sağlar. Her ne kadar bu sistemler eski bir gelenek olarak görülse de günümüzde sürdürülebilirlik çalışmaları kapsamında güncelliği artan bir teknolojidir.

Alanya ülkemizin tarihi çok eskilere dayanan bir yerleşim alanıdır. Özellikle Alanya Kalesi bölgesinde eski yerleşim izleri tarihin canlı kanıtları olarak varlığını sürdürmektedir. Alanya Kalesinde yapılan alan çalışmasında pek çok sarnıcın olduğu görülmüştür ve bazılarının halen kullanıldığı bilinmektedir. Bunlara önemli bir örnek olan Emine Cimrin Koçak evindeki sarnıç yapısı ve tekrar kullanımı açısından incelenmiş ve sarnıç yapılarının kullanımda olmasının olumlu olumsuz yönleri değerlendirilmiştir.

\section{Geleneksel Yağmur Suyu Toplama Sistemleri}

Hidrolojik döngüde bilinen ilk su formu olan yağmur suyu insanlığın birincil su kaynağıdır ve bu doğal kaynağın optimum şekilde kullanılması gerekmektedir. Yağmur suyun etkin 
şekilde kullanımı için yağmur suyu hasadı yapılacak ve muhafazası sağlanacak sistemlerin oluşturulması gereklidir. Yağmur Suyu hasadı ve muhafazasının yokluğunda, tamamen ikincil su kaynaklarına bağımlı oluruz bu ikincil su kaynakları da: nehirler, göller ve yeraltı sularıdır (Efe, 2006, s.40).

Yerleşimler genellikle ikincil su kaynaklarına yakın alanlarda oluşmuş olsa da yeterli yağış alan bölgelerde de yağmur hasadı yapılarak oluşturulan su kullanım imkanları sayesinde bu alanlarda da yerleşimlerin geliştiği görülmektedir. Yağmur suyu toplayarak genel su intiyacının karşılanması için çeşitli sistemlerin kullanımı çok eski tarihlere dayanmaktadır. Bu sistemler birçok kültürde farklı yapım ve uygulama şekilleriyle karşımıza çıkmaktadır (Hassan, 2016, s.213-222).

Yağmur suyunun çatılardan, açık araziden ahşap ve toprak (terrakotta) borular ya da su kanalları aracılığı ile yönlendirilerek yer üstü/ veya yer altı depolarda biriktirilmesi için yapılan çalışmalara 'Yağmur Suyu Hasadı' denir. 'Yağmur suyu hasadı, sulamada ve evsel kullanımda sürdürülebilir olmayan yer altı suyu kullanımına alternatif olarak yağışla yüzey akışına geçen suyun biriktirilip kullanılması için geliştirilen yöntemlerin bütünüdür" (Tokuş ve Özdemir, 2017, s.7). Yağmur suyu hasadı yapmak ve gerekli alanlara su sağlamak için kullanılan yöntemler arasında yağmur bahçesi, yağmur hendekleri ve sarnıçlar bulunmaktadır.

\subsection{Yağmur bahçeleri}

Yağmur bahçeleri esasen yüzey ve yüzey altı su filtrasyon sistemleridir. Müftüoğlu ve Perçin (2015)'e göre yağmur bahçelerinde kullanılan sistem, yağmur suyunun yeryüzünden akıp gitmemesi, düştüğü yerde alt tabakalara sızdırılması, toprağın suyu sünger gibi emebilmesi temeline dayanan akılcı, stratejik ve kolay bir uygulamadır. Kum filtreleri gibi işlev görürler; bununla birlikte, kum filtreleri yağmur suyunun bir kum ortamından geçişi yoluyla su kalitesi arıtımı sağlarken, yağmur bahçesi sistemleri, kirleticileri gidermek ve yağmur suyu akış hacimlerini azaltmak için hem bitkileri hem de alttaki filtre topraklarını kullanır (Müftüoğlu ve Perçin, 2015, s.27-37). Şekil 1'de yağmur bahçelerinin uygulama kesit detayı görülmektedir.

Yağmur bahçelerine tipik olarak kısa süreli doygunluğa (yani 12-96 saat) ve ardından daha uzun kuraklık dönemlerine dayanabilen otlar, çalılar ve ağaçlarla dikilir. Bitki örtüsü, önemli yağmur suyu hacimlerinin ortaya çıkmasına yardımcı olur, kirletici maddelerin uzaklaştırımasını artırır, toprak sıkışmasını azaltır ve alana ekolojik ve estetik değer kazandırır (Bhattacharya,2015, s.30-38). Yağmur bahçelerinin faydaları şu şekildedir (Dietz ve Clausen, 2005, s.123-138).

- Yüzey akışıyla gelen yağmur sularının temizlenmesinde doğal filtre görevi yaparak suyu temizlemek ve yeraltı sularının beslenmesini sağlamak,

- Uygulandığı yere özgü flora ve fauna için uygun ortam oluşturmak ve biyolojik çeşitliliği arttırmak,

- Yağmur sularının etkin olarak kullanımını sağlamak,

- Drenaj çözümlerine ekonomik ve sürdürülebilir imkân sunmak,

- Ortamın nem dengesinin korunmasına yardımcı olmak,

- Yağmur suyunun yüzey akış hızını düşürerek, kontrollü olarak akmasını sağlamak, beraberinde getirdiği toprak kaybını önlemek,

- Araç yolları, yürüyüş yolları ve otoparklar gibi sert yüzeyli alanlarda istenmeyen su birikintilerini toplayıp yönlendirerek doğaya geri kazandırmak,

- Estetik bir görünüm oluşturmak. 


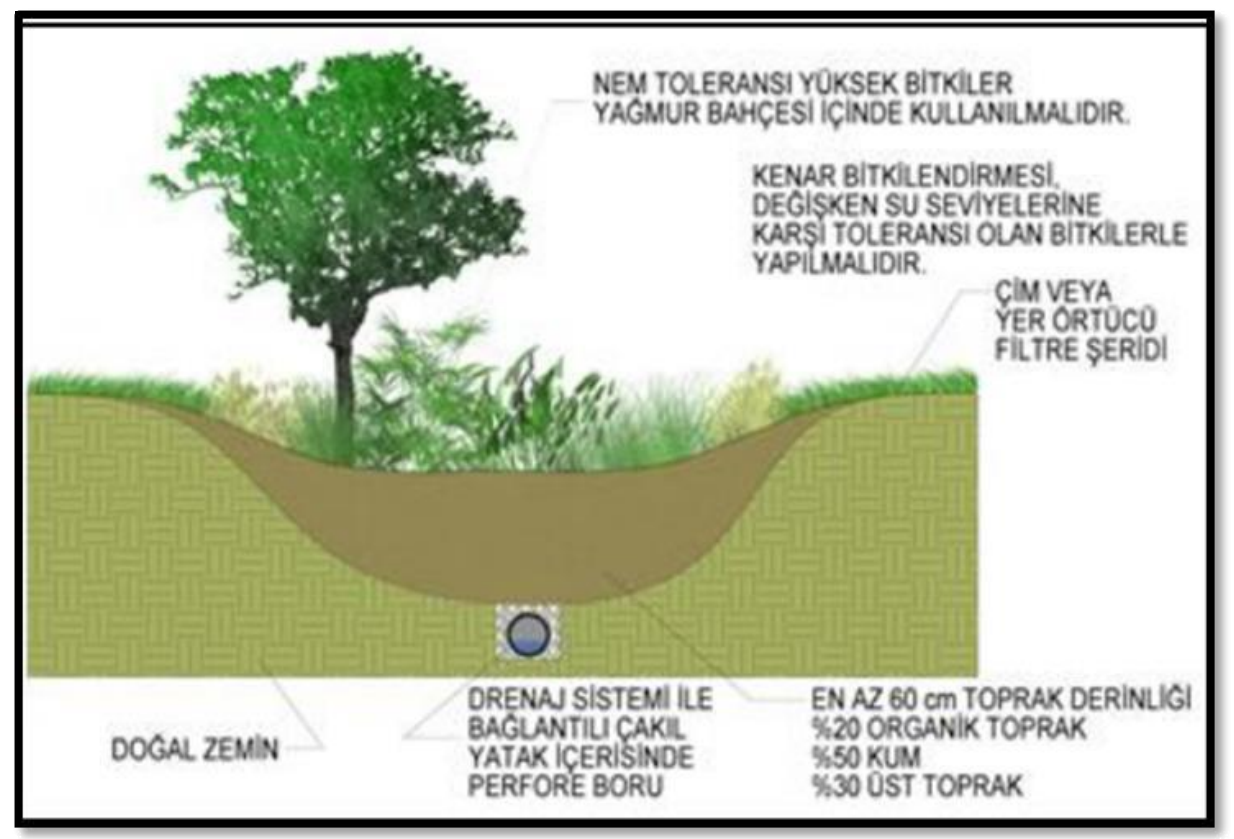

Şekil 1: Yağmur bahçesi (Karpuzcu, 2016).

Yağmur bahçelerinin yapımı dört aşamadan oluşmaktadır; bunlardan ilk aşama hazırlık, ikinci aşama yapım, üçüncü aşama dikim ve dördüncü aşama ise bakımdır. Yağmur bahçesi tasarlarken hazırlık aşamasında yapılacaklar sırasıyla yer seçimi, su taşıyan yüzeylerin belirlenmesi, toprağın test edilmesi ve bahçe boyutunun belirlenmesidir. Yapım aşamasında, su akışını tasarlama, toprağı kazma, taşma engelleme sınırı oluşturma, drenaj yapma, toprağı gübreleme ve toprak sermedir. Dikim aşamasında yapılacaklar, bitki seçimi, bitkilerin yerleştirilmesi ve malçlamadır. Son aşama olan bakım bölümünde ise, su akışı kontrolü, malç-toprak kontrolü ve bitki bakımıdır. Yağmur bahçelerinde kullanılacak bitkilerin, doğal bitki örtüsünden ya da o bölgeye uyum sağlamış bitkilerden seçilmesi gerekmektedir. Yağmur bahçeleri kurulduktan sonra özellikle de doğru bitkiler kullanıldığında düşük bakım gerektirir (Çevre ve Şehircilik Bakanlığı, 2018).

\subsection{Yağmur Hendekleri}

Sürdürülebilir sistemlerden biri olan yağmur hendekleri, yağmur suyundan maksimum fayda elde edilmesi için kullanılan ve dolayısıyla yağmur suyunu taşıma, arıtma ve yüzeysel akış miktarını azaltma amacıyla inşa edilen bitki örtülü açık kanallardır. Bu hendekler; yüzeysel akış hızını yavaşlatarak erozyonu önlemekte, taşkın pik debisinin oluşma zamanı geciktirmekte, yüzeysel akışa geçen yağmur suyu miktarını ve taşkın pik debisini azaltmakta, yeraltı su seviyesini arttırmakta ve yağmur suyundaki kirletici maddelerin uzaklaştırılmasını sağlamaktadır. Bu faydaları ve geleneksel sistemlere göre daha ekonomik uygulamalar olmasından dolayı sürdürülebilirlik açısından yağmur hendeklerinin kullanımlarının yaygınlaştırılması tavsiye edilmektedir (Ünal ve Akyüz, 2017, s.71-82). 


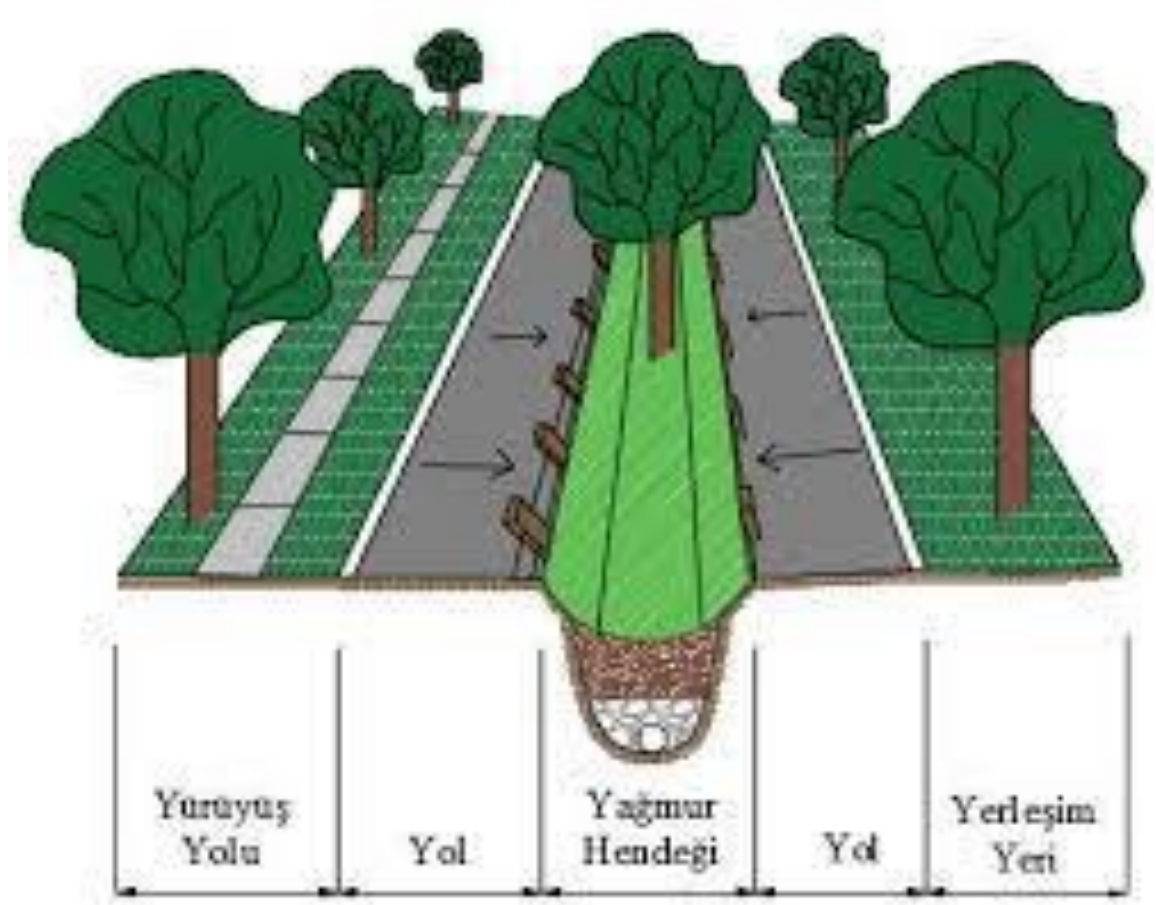

Şekil 2: Yağmur Hendekleri (Çetinkaya, 2019, s.22-23)

Yağmur hendekleri yerleşim bölgelerinde konutların çevresine ve bahçelere de inşa edilebilir. Bu alanlara inşa edilen yağmur hendekleri çatılardaki yağmur suyunun hasat edilmesini sağlar. Böylece çatılardan toplanan yağmur suyunun hendek içinde arıtılarak yeraltı suyuna karışması ve yeraltı su seviyesinin arttırılması sağlanır. Yağmur hendeklerinin tarımsal su hasadı amacıyla kırsal bölgelerdeki kullanımları da yaygındır. Bu hendekler arazinin topografyasına göre eş yükselti eğrilerine paralel olarak kazılır ve yağmur suyunu depolayarak bu suyu yeraltına sızdırır. Böylece üzerinde bulunan gıda ormanın su ihtiyacını karşılar ve bu sayede tarımdan elde edilecek verimin artmasına yardımcı olur (Şekil 2).

\subsection{Sarnıçlar}

Çoğunlukla yer altında bulunan sarnıç yapıları, yağmur suyu toplama ve depolama amaçlı kullanılmaktadır. M.Ö. III. bin yılında kullanılmaya başlandığı düşünülen bu yapılar insanlık tarihinin her çağında su sistemleri içinde inşa edilmiştir. Özellikle yakınlarında su kaynağı olmayan yerleşim bölgelerinde tercih edilmiş bu yapılara antik kentlerde sıklıkla rastlanmaktadır.

Kent içinde lokasyonları ve döneminin mimari özelliklerine göre sarnıçlar farklılık göstermektedir. Çoğunlukla gösterişten uzak sade bir yapı olan sarnıçların yapıldıkları dönem ve bulundukları coğrafyaya göre farklıııklar göstermektedir. Kapalı veya açık olarak inşa edilebilen sarnıçlar çoğunlukla yağmur suyunu toplamak amacı taşısa da zaman zaman kaynak suyu biriktirmek içinde inşa edilmiştir. Arkaik ve Klasik çağlarda dairesel ve dikdörtgen tiptedir. Helenistik Çağ'da yaygın olarak armut biçimli ya da şişe tipi olarak adlandırılan tiplerde inşa edilmiştir Şekil 3'te iki farklı sarnıç tipine ait görseller verilmiştir. 


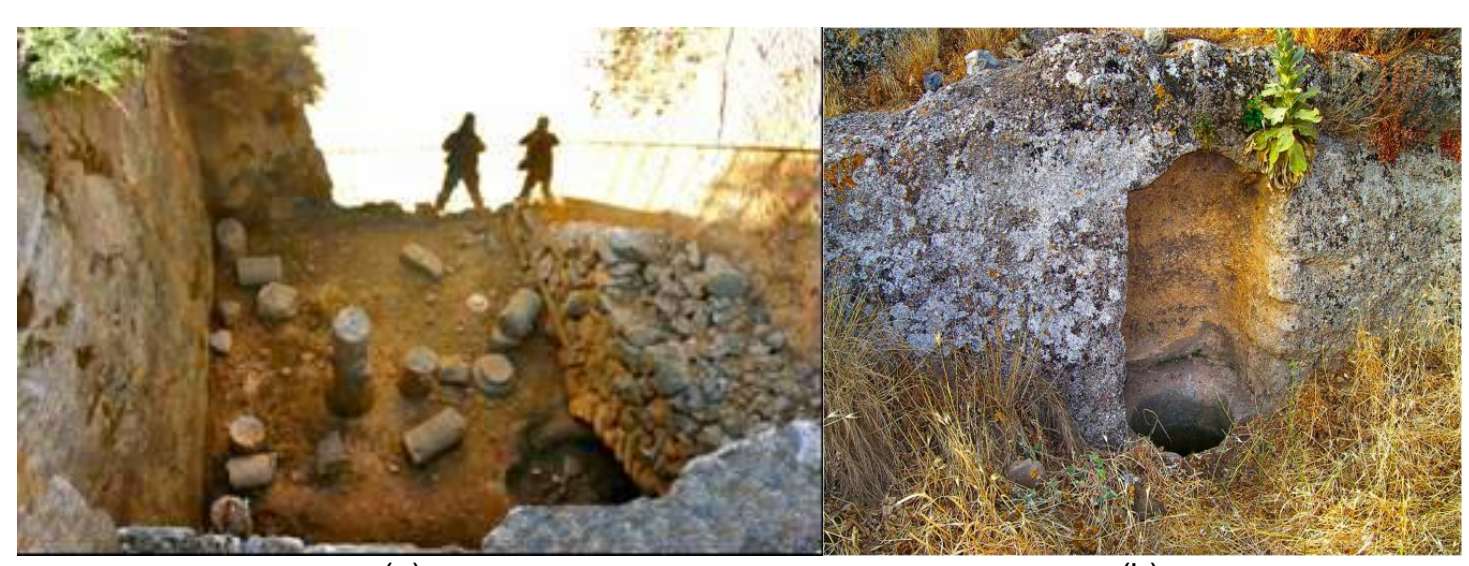

(a) (b)

Şekil 3: Girit'teki Helenistik sarnıçlar: (a) Lato kasabasında bulunan ve (b) oymalı sarnıç. Polyrrhenia kasabasındaki sarnıç (Yerli, 2019).

Roma Çağı'nda ise bir önceki dönemde kullanılan tiplerden çok uzaklaşımadığı fakat gelişen mimari ile kullanım amaçlarında çeşitlenme olduğu gözlemlenmiştir. Bu dönemde kent merkezlerinde çokça rastladığımız nymphaeum olarak adlandırılan çeşme yapılarının sarnıçlardan beslendiklerini gösteren birçok örnek bulunmaktadır (Yerli, 2019).

Sarnıç sistemleri yüzyıllar içinde yapım şekli ve malzemesi olarak değişim gösterse de toplumların vazgeçilmez yapılarından biri olmuştur.

Roma İmparatorluğu döneminde yağmur sularının toplanması pek çok yeni şehrin zamanın en son teknolojilerini bünyesinde barındırmasıyla gelişti ve suyun kullanım kolaylığının sayesinde bu şehirler döneminin sanat ve bilim merkezleri haline geldi.

Sarnıçların tarihsel süreci teknolojik açıdan incelendiğinde aşağıdaki sonuçlar ortaya çıkmaktadır;

i. Tarih boyunca sarnıçlar, su kaynaklarının sürdürülebilirliğini sağlayarak insan yaşamı ve refahı için su temin teknolojisinin önemli bir parçası olmuştur;

ii. Küçük ölçekli kullanımının yansıra (su toplama sistemleri için sarnıçlar gibi) büyük ölçekli su tedarik projelerinin (su kemeri akışlarını depolamak için sarnıçlar gibi) bir bileşeni olarak birçok eski uygarlık tarafından kullanılmıştır;

iii. Sarnıçların eski su teknolojileri tarihi eserler olarak değil, bugün ve gelecek için sürdürülebilir su teknolojileri için potansiyel modeller olarak görülmelidir;

iv. Sarnıçlar gibi eski su teknolojileri, basitlik, kullanım kolaylığı ve karmaşık kontroller gerektirmemesi ile karakteristik özelliklere sahiptir ve bu da onları daha sürdürülebilir hale getirmektedir (Mays, Antoniou ve Angelakis, 2013, 735-742). Aynı zamanda bu sistemlerin bazılarının başarılı tasarımı ve işletilmesi ile önemli mühendislik başarısı olarak tarihe geçmiştir;

v. Sarnıçlar, eski uygarlıklar tarafından su kaynaklarının sürdürülebilirliği için kullanılmış ve o zamandan beri kullanılmaktadır, ancak dünyanın gelişmekte olan birçok yerinde devam etmesine rağmen, günümüzün su temini amaçları için önemleri dünyanın gelişmiş bölgelerinde bir şekilde ortadan kalkmıştır (Eldem, 1954, s.25).

vi. Eskiler, su güvenliğini, su tedarik sistemlerinin tasarımı ve inşasının kritik yönlerinden biri olarak görüyorlardı.

Tüm bu özellikleriyle sarnıçların günümüzde de kullanılabilir olması ya da yerini teknolojik olarak daha gelişmiş sistemlere bırakması gerekirken tam tersi bir uygulama 
oluşmuş ve mevcut su kaynakları kontrolsüz şekilde kullanılmış ve kullanılmaya devam etmektedir. Bilinmektedir ki dünyamızın temiz su kaynakları hızla tükenmekte ve yerine yenisinin konması imkânsız hale gelmektedir. Bu durumda yağmur suyundan faydalanma stratejileri geçte olsa gündeme gelmekte ve önemine vurgu yapılmaktadır.

Bu kapsamda ülkemizde de çok sayıda örneği bulunan sarnıç başta olmak üzere inşa edilen su yapılarına Alanya Kalesi'nde rastlanmıştır. Hem kalenin iç kısmında hem de çevresindeki konutlarda farklı sarnıç sistemleri tespit edilmiştir.

\section{Geleneksel Alanya Evleri}

Alanya genelinde günümüze kadar ulaşan, 19.yy sonu ile 20.yy başına tarihlendirilen geleneksel Alanya evlerinin bir kısmı Alanya Kalesi surları içinde Tophane ve Hisariçi mahallelerinde, bir kısmı da surların dışında şehir merkezi ve çevre mahallelerde yer almaktadır. İçlerinde üç katlı olanları bulunsa da geleneksel Alanya evleri çoğunlukla zemin ve birinci kattan oluşan alçak müstakil yapılardır. Eski Alanya evlerinin zemin katları depolama, hayvan barındırma ve servis mekânlarına ayrılmış bölümlerden oluşur. Evlerin birinci katı ise asıl yaşam alanı olarak kullanılmaktadır. Hayvanların ve servis mekânlarının bulunduğu ve Alanya'da "Gedey" olarak adlandırılan bu bölümden, günlük yaşamın sürdürüldüğü "Hayat" bölümüne ahşap ya da taş merdiven ile çıkılır. Zemin katta bulunan gedey adı verilen bu bölümde bazen hane halkı dışından gelen misafirlerin kalabileceği odalar da bulunur. Bazı evlerde bugün de izlerini gördüğümüz, "Hayat" ve "Gedey"i birbirinden ayıran açılır kapanır ahşap kapaklar bulunur.

Asıl yaşam alanının yer aldığı birinci katta; ortak yaşam alanı olarak kullanılan hayat (sofa); büyük içeri (ebeveyn yatak odası), küçük içeri (genç ebeveynlere ait yatak odası), çağnişir (başoda), mabeyn (kalabalık misafir ağırlamalarında kadınlara ait oturma odası), çardak, mutfak ve tuvalet mekânlarını birbirine bağlar (Şener,1984, s.11). Alanya Kalesi'nde yer alan geleneksel sivil mimarlık örneği evler Eldem'in tanımladığı Dış Sofalı Plan Tipi olarak adlandırılan plan özelliklerini taşımaktadır (Akman, 2019, s.65). Sofaya açılacak şekilde dizilen odaların her biri ayrı bir yaşam alanı hatta odayı kullananın evi hanesi gibidir. Bu odalarda ocaklık ve yüklük bulunur. Yüklükler; yer yatakları, minder ve yorganın istiflendiği ahşaptan yapılma dolaplardır. Bu ahşap dolabın içinde çoğunlukla bir gusülhane bulunur. Dolapların üstü açık ve ahşap korkulukla çevrelenmiştir ve buraya "Musandere" denir. Musandereler yüklüğün üstünde kışlık meyvelerin ya da kuru gıdaların saklanması işlevini de görür. Ayrıca evlerin taş duvarlı kısımlarında da taş duvarın içine yerleştirilmiş niş şeklinde dolaplar bulunmaktadır (Eldem, 1954, s.25).

Alanya Kalesi Tophane Mahallesi geleneksel evleri hakkında 1974 yılında Dr. Hasan Şener tarafından 13 geleneksel konut üzerine yapılan araştırmada bu konutların tümünde ortak ve belirgin mekânsal ayrım dikkat çekmiştir. "Yazlık dilim" ve "kışlık dilim" olarak adlandırılan mekân organizasyon özellikleri şu şekilde belirtilmiştir:

"Hayat, Çağnişir, Mabeyn, Küçük İçeri ve Çardak hacimleri manzara yönündeki dilimi "Yazlık Dilim", Ebeveyn Yatak Odası (Büyük İçeri), Mutfak ve bazen de Küçük İçeri hacimlerinin bulunduğu dilimi "Kışlık Dilim" olarak tanımlamak mümkündür (Şener,1984, s.11).

Alanya Kalesi'nin coğrafi yapısı evlerin plan tipini etkilemiştir. Hayat, Çağnişir, Mabeyn, Küçük İçeri ve Çardak manzara yönünde yer alan yazlık dilim içinde, Büyük İçeri, Mutfak ve bazen Küçük İçeri kışlık dilim içinde yer almaktadır. El yıkama(abdestlik) ve tuvalet(helâ) her iki dilimde de yer alabilmektedir (Şener,1984, s.11). Türk Evi plân tipinde hamamlar, bina planı içinde yer alırlar. Helâlar ise, en eski tiplerde ekseriya evin 
haricindedirler. Evin içine alındıkları zaman sofanın ucuna veya bir ilâvesine yerleştirirler. Musluk da sofanın bir tarafına gelir (Eldem, 1954, s.25). Hamamlar evin içine alındığında ocağa ve suya yakın bir yere eklenir. Çoğu zaman mutfağa yakın bir bölme hamam olarak düzenlenir. Bazı evlerde abdestlik, helâ ve mutfağa bitişik gusülhaneler görünürken çoğunlukla ebeveyn odalarında da müstakil banyolar bulunmaktadır (Akman,2019, s.65). Gusülhane adı verilen bu küçük ıslak hacimler babanın abdest alması ya da yıkanması için düzenlenir. Bu düzenleme İslami bir zorunluluğu yerine getirmek için düşünülmüştür. İslami kurallara göre durgun suda yıkanılmadığından, küvet yerine dışarıdan taşınılan su dökünerek yıkanılır (Kuban, 1995, s.118). Ev içinde yer alan sarnıç damı genellikle mutfak zemini olarak kullanılmaktadır. Su sarnıçtan ipe bağlanmış bir kova yardımı ile çekilir. Suyun sarnıçtan alınan ve sarnıç ağzı ya da sarnıç bacası olarak adlandırılan bu kısım genel olarak mutfakta ya da mutfağa yakın bir yerde bulunmaktadır (Akman,2019,67). Günümüzde kullanılan sarnıçlardan su hâlâ bu yöntemle alınır. Konyalı şöyle anlatır: Su, sarnıçtan kova ile alınır. Alâiyye'liler sarnıçlara tulumba kurulmasını hoş görmüyorlar. Su kova ile dövüldükçe durulur ve dinlenirmiş (Konyalı, 1946,s.245.).

Mutfaklar, fırınlar ev içinde olmadığı zaman kendiliğinden plan harici kalmakta ve dolayısıyla ev planı üzerine bir tesirleri olmamaktadır. Ev içinde oldukları zaman ise, alt kattadırlar ve bu sebepten dolayı yine plan tipi üzerinde tesirleri yoktur (Şener,1984, s.11). "Anıt Envanter Fişleri”nden derlenen bilgilerin ışığında manzara yönündeki dilim, genel olarak zemin katta ahşap dikmeli, üst katta ahşap karkas üzerine ahşap kaplama bazen de kıtık sıvalı olarak oluşmuştur. Çatı genellikle eğimli alaturka kiremit örtülüdür. Diğer dilim, zemin ve üst katta taşıyıcı taş duvarlar (ahşap hatıllı, dışta sıvasız, içte sadece yaşam katında sıvalı) genellikle sıkıştırılmış killi toprak örtülü düz çatı(dam) olarak oluşmuştur (Şener,1984, s.11). Yapıların temel ve zemin kat duvarları, ahşap hatıllar atılarak moloz taş kullanılarak örülmüştür. Keski ile yontulan moloz taşların çevresi, cephelerde gelişigüzel yerleştirilmiş tuğla ve kiremit kırıkları ile doldurulmuştur. Manzara yönünde yer alan bölümlerde taşıyıcı ahşap dikmeler üzerine bağdadi çıtaların çakılıp sıvanması ile oluşturulmuş ahşap karkas strüktür olarak inşa edilirken, manzara yönünde olmayan mekânlarda zemin kattan gelen moloz taş duvar örgüsü devam ettirilmiştir.

Manzaraya bakan ahşap karkas üzeri sıvalı cephelerde, yöreye özgü demir parmaklıkları olan ahşap kapaklı pencereler bulunmakta ve çatı örtüsü alaturka kiremitli iken; manzara yönünde olmayan taş örgülü duvarlardaki pencereler daha az sayıda olup çatı örtüsü de toprak damdır.

Tarihi Yarımada'da su kaynaklarının kıt olması sarnıç kullanımını zorunlu kıımıştır. Yağmur suyu evlerin çatılarından, sur duvarlarının seyirdim teraslarından, bahçe duvarlarının üzerindeki oluklardan, açık arazide oluşturulan temiz su havzalarından derlenerek sarnıçlarda depolanmıştır.

Konut sarnıçlarının su tedariki yönteminde genel olarak evin kendi çatısı üzerine düşen yağmur suları, yağmur olukları aracılığıyla sarnıca yönlendirilmektedir. Hasat çatının bir bölümünden yapılmakta, çatı yüzeyine düşen yağışın bir kısmı sarnıca yönlendirilmekte böylece taşma riski ortadan kaldırılmaktadır (Akman, 2019, s.65).

\section{Emine Cimrin Koçak Evi Sarnıç Sistemi}

Alanya Kalesi tarihi boyunca yerleşim alanı olarak kullanılmıştır ayrıca bu alan Selçuklu döneminin önemli merkezlerinden biri olmuştur. Kale hem mimarisi hem de doğal güzelliği ile Akdeniz bölgesinin bir incisi gibi tarihi yarımadanın tepesine konumlanmıştır. 
Uzun yıllardan beri yerleşim merkezi olarak kullanılan kaledeki yapıların pek çoğu günümüze kadar varlığını korumuştur. Alanya Belediyesinin bu alanda yaptığı başarılı restorasyon çalışmaları ve kale içindeki Kültür bakanlığının çalışmaları ile tarihi yarımada tüm yerleşim alanı ile korunmaya devam etmektedir.

Sayısız konuta ev sahipliği yapan bu alanda döneminin teknolojilerinin de korunduğu görülmektedir. Bunlardan en dikkat çekeni kalenin tüm yerleşim alanında bulunan sarnıçlardır. Hem toplu kullanım için hem de özel konut kullanımları için inşa edilmiş çok sayıda sarnıç bu alanda yer almaktadır.

Tarihi Alanya Yarımadası üzerinde yer alan sarnıçlar, konutlar, hamam yapıları, ibadethaneler ve kamu sarnıçlarının her birinde yer alan su iletim sistemi fiziki koşullara göre şekillenen pratik çözümler geliştirmiştir. Kayalık ve su kaynakları açısından zayıf bir yapıya sahip Tarihi Alanya Kalesi'nde günümüze kadar korunarak gelen su iletim sistemlerinin varlığı yüzey ve alan araştırmaları sırasında tespit edilerek kayıt altına alınmaktadır.

Öyle ki konutların belirlenmesinde sarnıç sistemlerinin keşifleri yapısal özelliklerini kaybetmiş konut alanlarının tanınmasında büyük önem taşımaktadır. Hatta şöyle denebilir kalede bulunan her küçük sarnıcın bulunduğu yerde bir konut vardır.

Bunlardan Emine-Murat Kocak Evi hem tarihi yarımada siluetine olan etkisi hem de özgün özelliklerini çoğunlukla korumasıyla diğer yapılar arasında dikkat çekmektedir. Şekil 4'de Emine-Murat Kocak Evi'nin restorasyon öncesi ve sonrası hali görülmektedir.

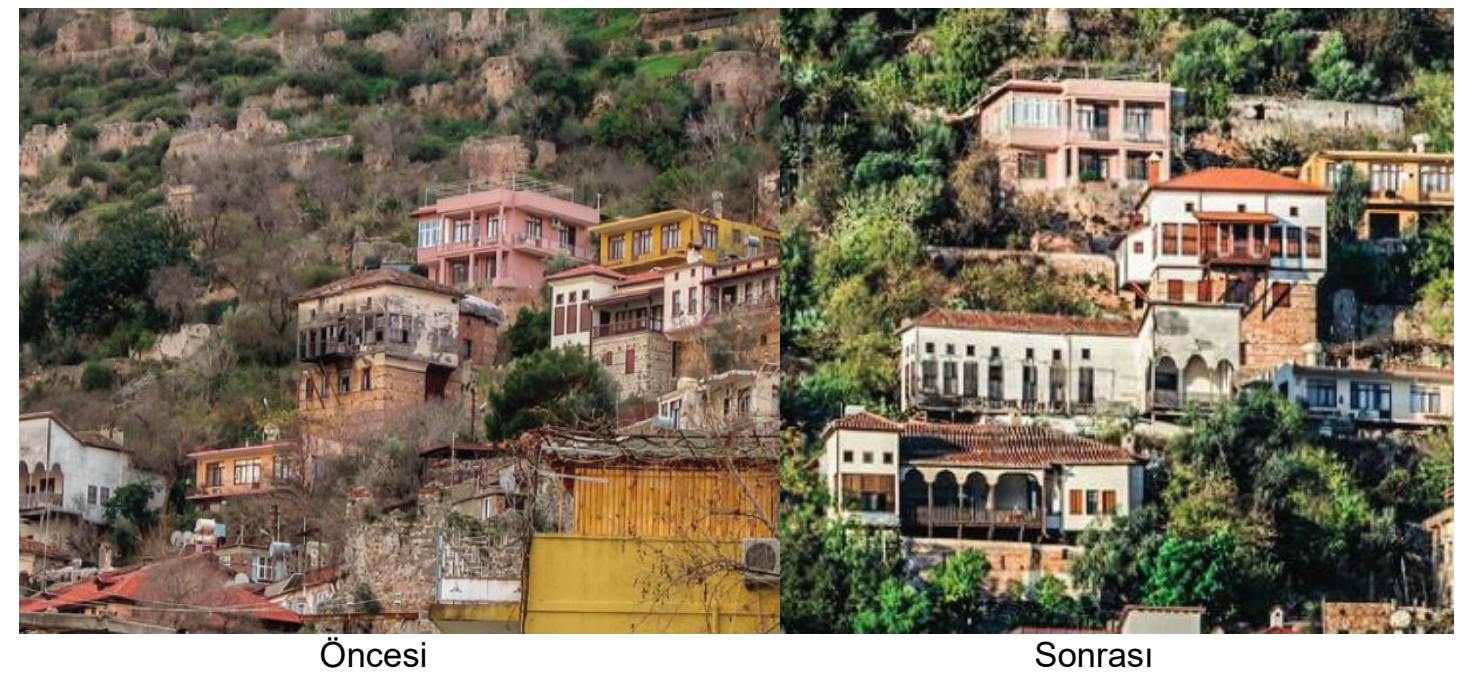

Şekil 4: Emine-Murat Kocak Evi'nin restorasyon öncesi ve sonrası hali (Koçak, 2016, s.312)

Konutlar içinde inşa edilmiş sarnıç sistemlerinden yakın zamanda restore edilerek kullanıma açılmış bir örneği Emine-Murat Kocak Evi'nde aktif olarak kullanıldığı tespit edilmiştir. Restorasyonunun bizzat Mimar Emine Cimrin Koçak tarafından yapılan konut projesi başarılı bir restorasyon süreci geçirmiştir.

Tophane Mahallesi 295 ada 3 parsel 'de yer alan ve Kültür Varlığı olarak tescillenen Emine-Murat Koçak Evi günümüzde de işlevini sürdüren "Yağmur suyu Hasat Sistemi" ile geçmişin su izini geleceğe taşıması açısından önemli bir örnektir. Konuta ait planlar Şekil 5'de gösterilmiştir ve bu planlarda sarnıcın yeri açıkça görülmektedir. 
Geleneksel Sürdürülebilir Yağmur Suyu Depolama Yöntemleri; Emine-Murat Cimrin Koçak Evi Sarnıcının İncelenmesi ve Yeniden Kullanımının Değerlendirilmesi

Traditional Sustainable Rainwater Storage Methods; Investigation and Reuse Evaluation of Emine-Murat Cimrin Koçak House Cistern

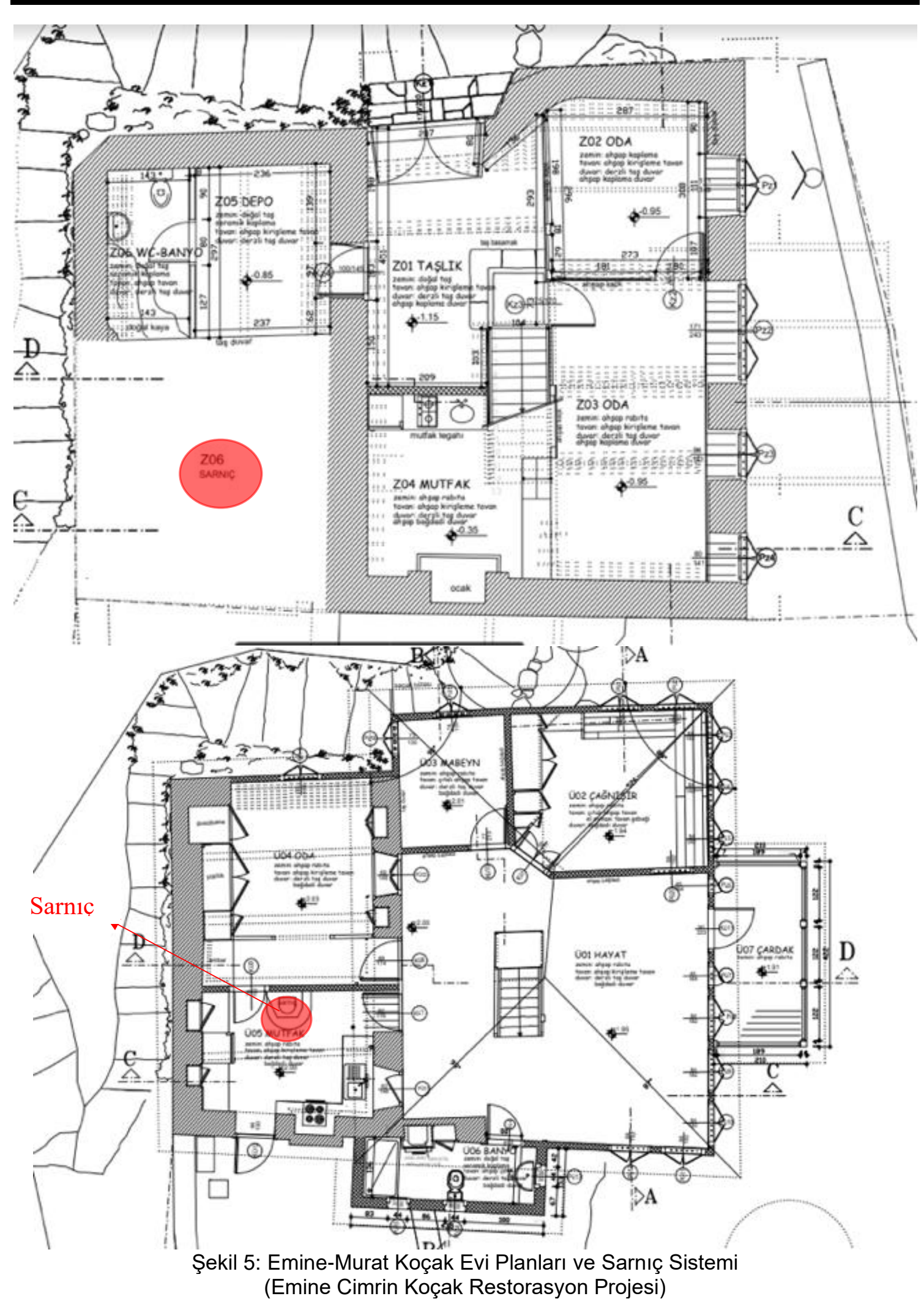

"Konut sarnıçlarının su tedarik yönteminde genel olarak evin kendi çatısı üzerine düşen yağmur suları, yağmur olukları aracılığıyla sarnıca yönlendirilmektedir. Hasat, çatının bir bölümünden yapılmakta, çatı yüzeyine düşen yağışın bir kısmı sarnıca yönlendirilmekte böylece taşma riski ortadan kaldırılmaktadır. Evlerin düz toprak dam yüzeyi ya da kiremit çatı yüzeyinin bir bölümünde çatı oluk sistemi oluşturulmaktadır." (Akman, 2019, s.67). 
"Yatay ve düşey yağmur olukları aracılığı ile çatıdan uzaklaştırılan sular ilk yağmurlarda sarnıçlara bırakılmaz. Öncelikle çatı yüzey temizliğinin sağlanması için bol yağışlı mevsim beklenir. Yağmur suyunun çatıdan sarnıca aktarımını sağlayan ahşap oluk çatının tamamından gelen suyu sarnıca vermez. Genelde sarnıcın bulunduğu taraftaki toprak dam yüzeyinden, ya da kiremit örtülü kısımdan su kontrollü olarak içeriye alınır" (Akman, 2019, s.65).

Emine-Murat Koçak Evi su İletim sistemi; kiremit çatı yüzeyinin bir tarafında oluşturulan metal oluk sistemi ile hasat edilerek evin mutfak bölümünde yer alan sarnıca yönlendirilmektedir. Bu sisteme ait çatı detayı ve oluk sistemi Şekil 6.'de görülmektedir.

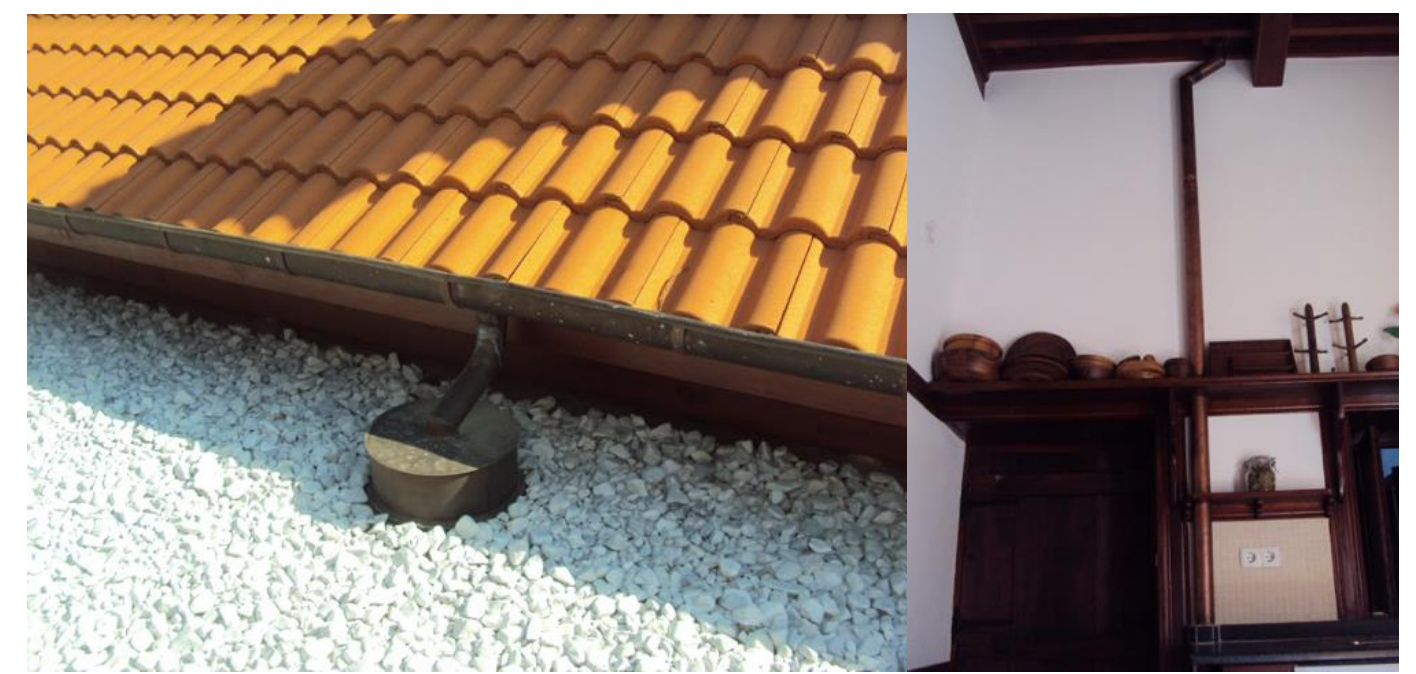

Şekil 6: Emine-Murat Koçak Evi yağmur suyu toplama çatı detayı ve oluk sistemi (Fotoğraflar: Nilgün Akman)

Restorasyon sırasında sarnıç izolasyonu geleneksel yöntemler kullanılarak restore edilmiştir. Mutfak kısmında bulunan sarnıç ağzı ya da sarnıç bacası kullanılarak su, bir ipin ucuna bağlanan kova aracılığı ile çekilerek kullanılmaktadır. Alanya Kalesi yaşayanları sarnıç suyunun su motoru aracılığı ile çekilesini doğru bulmazlar. Sarnıç suyu kova ile çekilmelidir. İpin ucundaki su kovası su yüzeyine ulaştığında kova yukarıaşağı çekilerek birkaç kez su yüzeyine vurulur. Buna kovanın suyu dövmesi denir. Böylece su yüzeyinde olduğu varsayılan tozların, suyun dibine çökeceği ve çekilen suyun temiz olacağına inanılır. Şekil 7'de sarnıcın konut içindeki görünümüne ait görsel bulunmaktadır. 


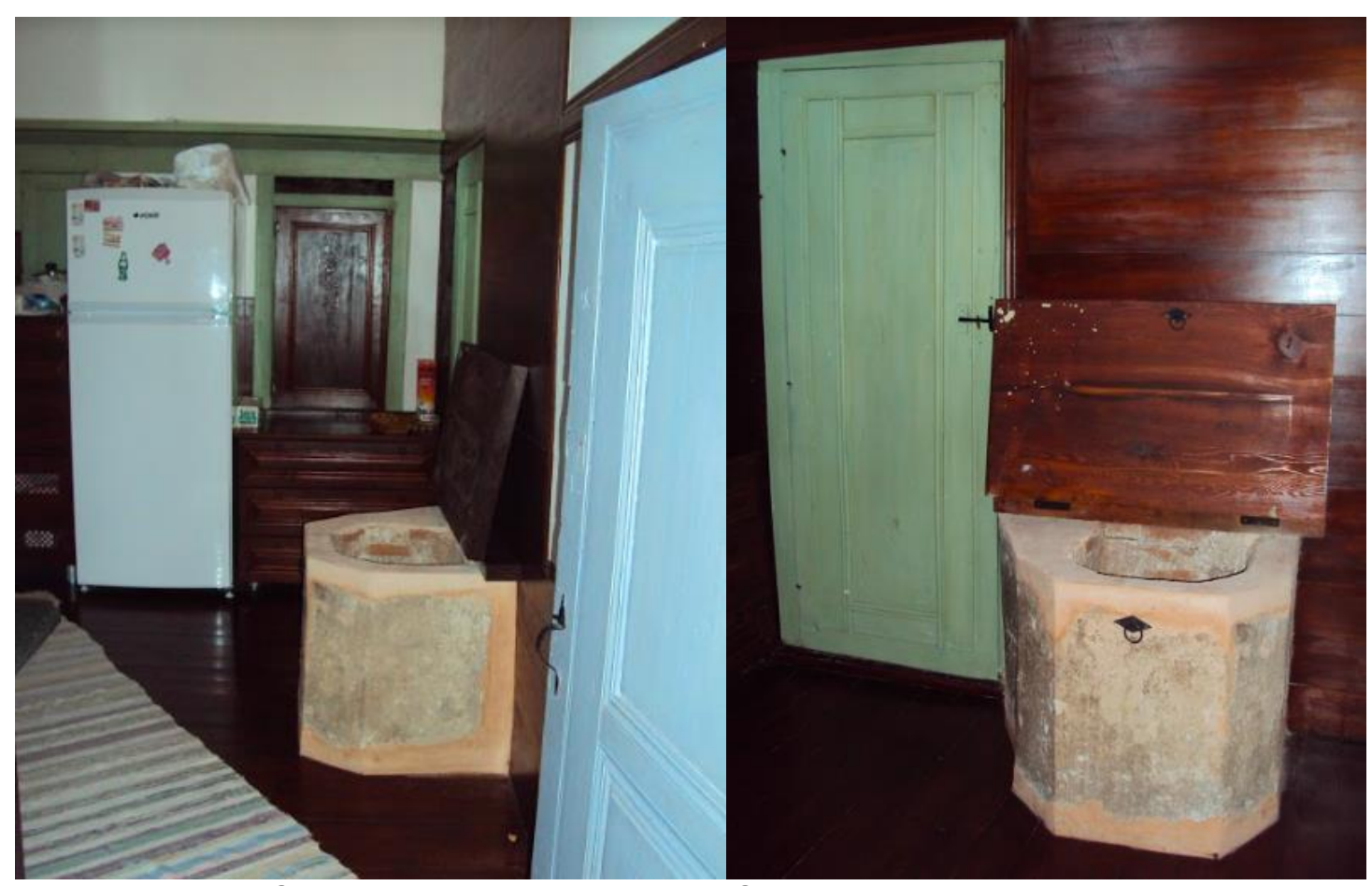

Şekil 7: Emine-Murat Koçak Evi Sarnıç konut içi görüntüsü

(Fotoğraflar: Nilgün Akman)

Emine-Murat Koçak Evi'nin sarnıç sistemini evin sahiplerinden Emine Cimrin Koçak, "Evimizin en büyük zenginliklerinden biri de zemin katta bulunan ve ağzı mutfak (küçük içeri) mekânına açılan su sarnıcıdır. Bu su sarnıcı genel olarak iyi durumdaydı fakat sarnıca çatıdan su taşıyan sistem hasar görmüştü. Bu sistemi de onarıp sarnıcımızı tekrar yağmur suyunu toplar hale getirdik. Evin tamamında taş duvarlar içinde bağlayıcı olarak toprak kullanılmıştı. Ancak sarnıç kireç, kiremit kırıkları ve tozları, doğal kum karışımından oluşan bir harçla yapılmıştı. Ardından da bu harcın daha ince olanı ile sıvanmıştı. Asıına uygun olarak onarımımızı tamamladık. Sarnıcı bugün mutfağımızın içinden bir kuyu gibi kullanabiliyoruz. Yaklaşık 27 ton su almakta ve Alanya'da yağmurlar başladığında Kasım ayında doluyor. Bu vakitten sonra yağan yağmurlar yaptığımız bir taşma borusu ile dışarıya, bahçeye akıyor. Böylesine bir su kaynağı bugün de yaygın olarak kullanılmalı diye düşünüyorum." şeklinde anlatmıştır (Koçak, 2016, s.302-320).

\section{SONUÇ}

Alanya Kalesi'nde bulunan konut sarnıçlarına ülkemizin pek çok yerinde rastlanmaktadır. $\mathrm{Bu}$ sistem temiz su kaynaklarının kullanımının azaltılmasında büyük ölçüde fayda sağlamaktadır. Tarihi yapılarda bulundukları çağın gerekliliklerine uygun şekilde tasarlanana konut içi sarnıç sistemlerinin günümüzde de kullanılması gerekliliği son zamanlarda sürdürülebilir mimari kapsamında da üzerinde çok durulan bir konudur. Hali hazırda temiz su kaynakları bir şekilde konutlarımıza ve iş yerlerimize yani insanın kullanımının olduğu her alana kolaylıkla ulaşabilmektedir. Ancak son 10 yıllık su analizleri sonucunda temiz su kaynaklarının ömrünün artık sanıldığı kadar uzun olmadığı gözler önüne serilmektedir. Bu açıdan bakıldığında gri su kullanımının teşviki temiz su kullanımını azaltarak temiz su kaynaklarının ömrünü arttırabilecektir.

Emine-Murat Koçak Evi'nin sarnıç sistemi yağmur suyu kullanımını günümüzde de devam ettirmesi açısından değerlendirildiğinde çok önemlidir. Hem tarihi yapılardaki bu teknolojilerin yeniden kullanılır olması açısından hem de konut içi gri su kullanımının 
günümüz teknolojileriyle birleştirilerek yeni yapılacak yapılarda kullanımına olanak sağlayacak sistemlere örnek olması açısından yol gösterici olarak değerlendirilebilir.

Hiç kuşkusuz gri su sistemleri yeni yapılarda sürdürülebilir mimari kapsamında kullanılmaktadır. Bu sistemler gerek yeşil bina değerlendirme sistemleri gerek yeşil bina destekleyici kurumlar tarafından son derece önem verilen ve desteklenen bir uygulamalardır. Su toplama sistemleriyle konut içinde depolanan gri su bahçe sulamada ve tuvaletlerde kullanıma oldukça uygundur. Gün içindeki kullanım oranlarına bakıldığında sadece bu iki alanda bile kullanılan gri su temiz su kaybının büyük ölçüde önünde geçebilmektedir. Bu açıdan bakıldığında gri su sistemleri teşvik edilmeli ve özellikle yerel yönetimlerin imar yönetmeliklerinde gri su kullanımı ile ilgili zorunlukların oluşturulması gereklidir.

Bu çalışma alan çalışması ile belirlenen sarnıç sisteminin yeniden kullanımına dikkat çekmek ve yeni yapılarda günümüz teknolojisine uygun benzer uygulamalar için araştırma alanı oluşturmayı hedeflemiştir.

\section{KAYNAKLAR}

Akman, N. (2019), Tarihi Alanya Kalesi'nde Su: Elde Edilmesi ve Kullanımı, Yüksek Lisans Tezi, AlanyaHEP Üniversitesi, s.65, Antalya.

Bhattacharya, S., (2015), Traditional water harvesting structures and sustainable water management in India: A socio-hydrological review. International Letters of Natural Sciences, s.30-38.

Çetinkaya, A., (2019), "Sürdürülebilir Yağmur Suyu Depolama Yöntemleri: Muğla Yöresi Kırsal Sarnıçlarının Araştırılması ve Msk Merkez Yerleşkesi İçin Alternatif Çözüm Önerilerinin Geliştirilmesi”, Çevre Bilimleri Anabilim Dalı,Yüksek Lisans Tezi, Fen Bilimleri Enstitüsü, Muğla, s.22-23.

Çevre ve Şehircilik Bakanlığı Mekansal Planlama Genel Müdürlüğü Kentsel Tasarım Dairesi Başkanlığı, (2018), Yağmur Bahçesi Hazırlama Klavuzu, web sitesi,http://www.cevresehirkutuphanesi.com/assets/files/slider_pdf/dG8NBCmfp8Dh.p df. Erişim Tarihi: 12.03.2021.

Dietz, M., Clausen, J., (2005), A Field Evaluation of Rain Garden Flow and Pollutant Treatment, Water, Air, and Soil Pollution volume 167, s.123-138.

Efe M., (2006), Atıksu ve yağmur suyu toplayıcı sistemlerinin tasarımı ve işletilmesinde kullanılan bilgisayar destekli modellerin değerlendirilmesi ve bir örnek uygulama, Yüksek lisans tezi, İstanbul Teknik Üniversitesi Fen Bilimleri Enstitüsü, İstanbul, s.40.

Eldem, S. H., (1954), Türk Evi Plan Tipleri, İstanbul,s.25.

Hassan, I. (2016). Rainwater Harvesting- an alternative water supply in the Future for Pakistan. Journal of Biodiversity and Environmental Sciences, 8(6), 213-222.

Karpuzcu, E., (2016), Sürdürülebilir Kentsel Drenaj Sistemleri (SKDS), Web sitesi, http://www.ekolojika.com/surdurulebilir-kentsel-drenaj-sistemleri-skds/. Erişim Tarihi: 25, 04, 2021. 
Geleneksel Sürdürülebilir Yağmur Suyu Depolama Yöntemleri; Emine-Murat Cimrin Koçak Evi Sarnıcının İncelenmesi ve Yeniden Kullanımının Değerlendirilmesi

Traditional Sustainable Rainwater Storage Methods; Investigation and Reuse Evaluation of Emine-Murat Cimrin Koçak House Cistern

Koçak, E. (2016), Mimarın Kendi Evi: 150 Yaşında Bir Alanya Evinin Restorasyon Serüveni, Ahşap Yapılarda Koruma ve Onarım Sempozyumu 4, s.302-320, İstanbul.

Konyalı, İ.H. (1946), Alanya (Alâiyye) Tarihi, İstanbul, Ayaydın Basımevi, s.245.

Kuban, D. (1995) Türk “Hayat”ı Evi, İstanbul, MTR Yayıncılık, s.118

Mays, L., Antoniou, G.P., and Angelakis, A.N. (2013). History of water cisterns: legacies and lessons. Water 5 https://doiorg/10.3390/w5041916.

Mays, L.W., (2013), Use of cisterns during antiquity in the Mediterranean region for water resources sustainability. Water Sci. Technol. Water Supply 2013 (13): 735-742.

Müftüoğlu, V., \& Perçin, H. (2015). Sürdürülebilir Kentsel Yağmur Suyu Yönetimi Kapsamında Yağmur Bahçesi. İnönü Üniversitesi Sanat ve Tasarım Dergisi, 5(11), s.2737.

Şener, H. (1984) Alanya'da Geleneksel Konutlar, İstanbul, Fak Baskı Atölyesi, s.11

Tokuş, C. M. ve Özdemir, G. (2017). Yağmur Hasadı Uygulamalarına Giriş Rehberi:İklim Değişikliğine Uyum Kapsamında Bir Çözüm Önerisi, Peyzaj Araştırmaları Derneği, s.7, Ankara.

Ünal, U., \& Akyüz, D. E., (2017), Sürdürülebilirlik A ısından Yağmur Hendekleri, Academia Journal of Engineering and Applied Sciences,Akademia Mühendislik ve Fen Bilimleri Dergisi, s.71-82.

Yerli, G., (2019), Assos Su Yönetimi, Sosyal Bilimler Enstitüsü, Yüksek Lisans Tezi, Çanakkale Onsekiz Mart Üniversitesi, Çanakkale. 